studies of bile pigment metabolism in the horse, a species in which urobilinoids are present in the fæces, yet in which the bile apparently contains no bilirubin.

Much of the earlier experimental results concerning amounts of the various bile pigments in the body fluids and excretions might with advantage have been condensed into a table and in some cases omitted altogether except perhaps from the list of references; all too frequently the earlier work was carried out with inadequate methods, and certainly in the case of the urobilinoids the substances were estimated without a pure preparation available as standard. Although Dr. With rightly criticizes these techniques, he still presents the results obtained by them.

The van den Bergh reaction is dealt with in remarkable detail, and although the precise proportions, amounts and concentrations of the various reagents which have been used are important in facilitating a correlation with the result obtained, the thirty-odd pages devoted to this subject make heavy reading, especially with so much in small type. The impartial presentation of the results of various workers sometimes introduces unintentional contradictions. For example, on p. $156 \mathrm{Kitchling}$ and Kuhn are quoted as showing that strong solutions of bilirubin after treatment with the diazo reagent do not follow Beer's Law because of insufficiency of reagent; on the other hand, three pages later there is an account of the work of Bungenburg de Jong, who has shown that the reagent is in good excess. Dr. With's accounts of the research of the last worker are especially valuable to the English reader, for they were mainly published in Dutch or German.

Seven addenda bring the subject-matter up to date and deal with the major works published between 1951 and 1953. One of these has a useful account of Hanson's in vivo work on rat livers, with fluorescence microscopy and uranin as an indicator for the biliary tracts. This is interesting work, but Dr. With doubts whether the distribution of uranin is likely to be the same as that of bilirubin. Another of these addenda describes work by Bourrillon, a member of the Polonovski school. This was published as a thesis and has not been generally available. Bourrillon has disproved the view of this group that the direct diazo reaction of certain sera was due to linkage of the bilirubin with globin. The work of Cole and Lathe, who have demonstrated by reversed phase partition chromatography the existence of two polar pigments which give direct diazo reactions, has been adequately summarized and discussed in a page inserted after binding was complete.

This monograph was originally intended to be printed in the United States; but its length prevented this and it has been produced by a Danish publisher in mimeograph on one side of crown quarto pages. The resulting volume, bound simply between boards which measure eleven and a half inches by eight inches, is two and a quarter inches thick, weighs six pounds and is not very manageable. 'The author's English is excellent, although its phraseology is sometimes quaint; there are innumerable typing errors-no doubt due to a non-English proof reader -but at no point is there ambiguity or obscurity. The figures have been moderately well reproduced and mostly tend to illustrate some of Dr. With's own research. Presumably because of the form of publication, it has not been possible to illustrate some subjects which would have been better understood with a figure-for example, the work on the biosynthesis of the porphyrins. The large pages crowded with type, often small, make for difficult continued reading. The book is not intended for the general reader; it is essentially a book of reference for specialist workers, and for them Dr. With has performed a signal service.

C. H. Gray

\section{ECOLOGY OF FRESHWATER MOLLUSCS}

An Introduction to Molluscan Ecology

Distribution and Population Studies of Fresh-water Molluses. By Dr. Alan Mozley. Pp. $x+72$. (London: H. K. Lewis and Co., Ltd., 1954.) 9s. net.

HIS slender volume forms the fourth in a series by Dr. A. Mozley on freshwater molluses, their ecology, control and relation to mankind. In some parts of the world certain species of water snails carry the larval stages of the parasites responsible for the dangorous diseases, urinary and intestinal schistosomiasis, affecting 5 per cent of the human race, and others convey the parasite causing liver rot in sheep; but not all water snails are harmful, and Dr. Mozley is here concerned with the ecology of freshwater molluses in general. As an authority on schistosome-carrying snails, he is naturally most interested in harmful species; but his experience in Siberia, Africa, Finland and Canada has enabled him to produce a little book packed with useful information and provocative thought on both harmful and harmless species.

In seven chapters he deals with limiting factors in distribution, living conditions, representative populations, dangerous localities, local economy, practical considerations and conclusions. There is also an appendix of four sections, explaining scientific details and methods of work for non-scientific readers. The index is adequate. Fourteen beautiful illustrations, chiefly of lake habitats, are seattered through the text; but unfortunately there is no picture of the snails, and a plate of the chief carriers, such as Physopsis, Biomphalaria and Lymnaea truncatula, would have been helpful.

Dr. Mozley is optimistic that schistosomiasis could be brought under control, since the molluscan hosts are "highly sensitive to conditions in the place in which they live", are a menace chiefly in suburban areas and where dense local populations of snails and humans occur, and can be killed, with their parasites, by treatment with copper sulphate at monthly intervals.

Throughout the book one is reminded of the problem of malaria, and of the importance of Sir Malcolm Watson's insistence on "species sanitation". As in malaria control, the problem is a local one, and it demands first and foremost an accurate knowledge of freshwater snails, their habits and habitats. Beyond that, persistence, planning and foresight are needed. Much good work is being done in Egypt under Dr. A. Halawani, director of the Fouad I Institute of Research and Hospital for Tropical Diseases, Cairo. But man in his ignorance and carelessness has brought about a spread of the disease through the Rhodesias to South Africa, and it is still extending its range. "If preventable, why not prevented ?" Dr. Mozley's final words are: "There $\begin{array}{ll}\text { is work to be done". } & \text { N. B. EALES }\end{array}$ 